\title{
BROOKHTHEN
}

NATIONAL LABORATORY

BNL-98039-2012-CP

\section{Methods of Reducing Vehicle Aerodynamic Drag}

\author{
Upendra S. Rohatgi \\ Presented at the ASME 2012 Summer Heat Transfer Conference \\ Puerto Rico, USA \\ July 8-12, 2012
}

July 2012

\author{
Nonproliferation and National Security/Safeguards and Verification \\ Implementation/Building 197D \\ Brookhaven National Laboratory
}

\section{U.S. Department of Energy}

Notice: This manuscript has been authored by employees of Brookhaven Science Associates, LLC under Contract No. DE-AC02-98CH10886 with the U.S. Department of Energy. The publisher by accepting the manuscript for publication acknowledges that the United States Government retains a non-exclusive, paid-up, irrevocable, world-wide license to publish or reproduce the published form of this manuscript, or allow others to do so, for United States Government purposes.

This preprint is intended for publication in a journal or proceedings. Since changes may be made before publication, it may not be cited or reproduced without the author's permission. 


\section{DISCLAIMER}

This report was prepared as an account of work sponsored by an agency of the United States Government. Neither the United States Government nor any agency thereof, nor any of their employees, nor any of their contractors, subcontractors, or their employees, makes any warranty, express or implied, or assumes any legal liability or responsibility for the accuracy, completeness, or any third party's use or the results of such use of any information, apparatus, product, or process disclosed, or represents that its use would not infringe privately owned rights. Reference herein to any specific commercial product, process, or service by trade name, trademark, manufacturer, or otherwise, does not necessarily constitute or imply its endorsement, recommendation, or favoring by the United States Government or any agency thereof or its contractors or subcontractors. The views and opinions of authors expressed herein do not necessarily state or reflect those of the United States Government or any agency thereof. 


\section{Methods of Reducing Vehicle Aerodynamic Drag}

\author{
Volodymyr Sirenko \\ Yuzhnoye State Design Office, Ukraine \\ Roman Pavlovs'ky \\ National Aviation University, Ukraine \\ Upendra S. Rohatgi \\ Brookhaven National Laboratory, USA
}

\begin{abstract}
A small scale model (length $1710 \mathrm{~mm}$ ) of General Motor SUV was built and tested in the wind tunnel for expected wind conditions and road clearance. Two passive devices, rear screen which is plate behind the car and rear fairing where the end of the car is aerodynamically extended, were incorporated in the model and tested in the wind tunnel for different wind conditions. The conclusion is that rear screen could reduce drag up to $6.5 \%$ and rear fairing can reduce the drag by $26 \%$. There were additional tests for front edging and rear vortex generators. The results for drag reduction were mixed. It should be noted that there are aesthetic and practical considerations that may allow only partial implementation of these or any drag reduction options.
\end{abstract}

\section{INTRODUCTION}

The issue of reducing the vehicles power consumption emerged nearly at the same time when vehicle itself was invented. In the beginning fueling stations were few and a low-consumption vehicle was needed to cover the longest possible distance, between refueling. Since, the number of cars has grown with the increase in fuel cost, it became again important to reduce the fuel consumption, both to save fuel but also the environment.

Vehicle power consumption reduction can be achieved by various means such as improved engine efficiency and aerodynamic drag reduction. From the early days, the designers recognized the importance of drag reduction and tried to streamlined the design. Since the early 20-th century, large number of studies were carried out in this field and some are listed here[1-6]. This was also the time of formulating of basic principles of vehicle body optimization, and definition of drag lower limit. For a perfect car body configuration the lowest possible aerodynamic drag coefficient is $\sim 0.16$.

Simulating road conditions has an effect on drag in the wind tunnel [4] and it is concluded that use of smooth immovable screen gives good result for comparative tests. The rear part of the vehicles make large contribution to the total drag and different forms of vehicle rear section has been studied [5]. In an interesting study [6], effect of variation in front and rear sections of minibus on total drag coefficient was presented. There is a good publication [3] evaluating different designs of vortex generators.

The vehicles operate under different speeds, air flow rate and direction, and road conditions. No one streamline body will minimize drag for all conditions. Therefore, there is need to develop passive devices that will keep drag coefficient low for large range of conditions or active methods that can dynamically change configuration to meet different speeds.

\section{INVESTIGATION METHOD}

There are various approaches of passive devices to reduce drag. These are,

- front screens;

- rear screens;

- structural elements that localize the area of flow detachment (edging);

- vortex air flow generators;

- deflectors located over the rear part of vehicle's roof;

- four-element rear fairing and its components;

- front fairing.

A two prong study was undertaken, Computational Fluid Dynamic (CFD) approach and testing large models in the wind tunnel under simulated conditions. This paper deals with the results of investigations in wind tunnel of a vehicle model with various passive devices for drag reduction.

The investigations were carried out in wind tunnel TAD-2 of the National Aviation University of Ukraine (NAU). Wind tunnel has the following main characteristics:

- maximum speed of air flux in working section without model installed is $42 \mathrm{~m} / \mathrm{sec}$;

- degree of initial turbulence of air flux in working section without model, defined using ball method, is $0.9 \%$;

- length of working section is $5.5 \mathrm{~m}$;

- overall dimensions of octagonal working section cross-section are: $4.0 \mathrm{~m}$ width, $2.5 \mathrm{~m}$ height; as shown in Figure 1.

During tests it is possible to measure total vector of aerodynamic forces and moments that affect model as well as pressure distribution over model's surface. Wind tunnel TAD2 was put into service in 1979 and was used many times for Ukrainian aviation and space rocketry. 


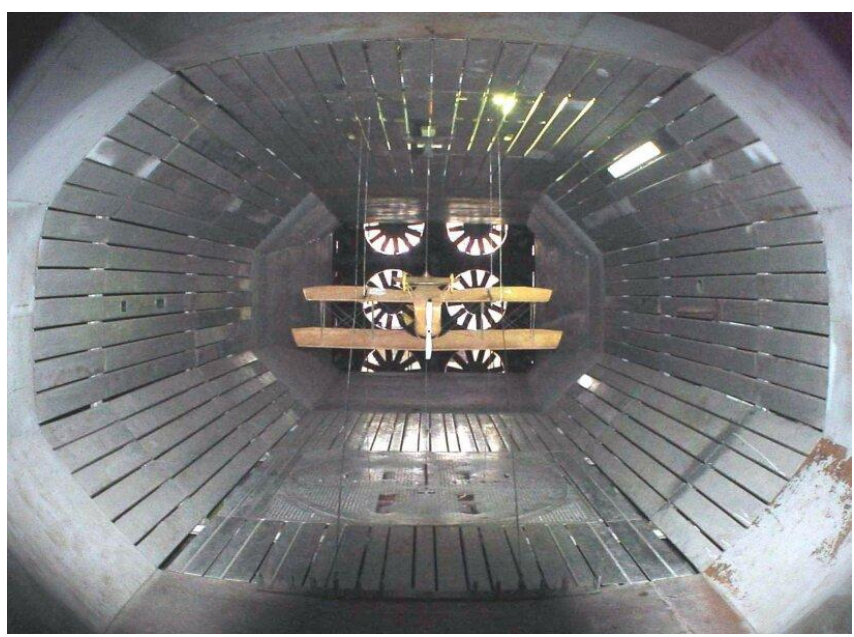

Figure 1

\section{INVESTIGATIONS TASKS AND PURPOSE}

The vehicle model tested is shown in Figure 2. The model length is $\mathrm{L}=1710 \mathrm{~mm}$.

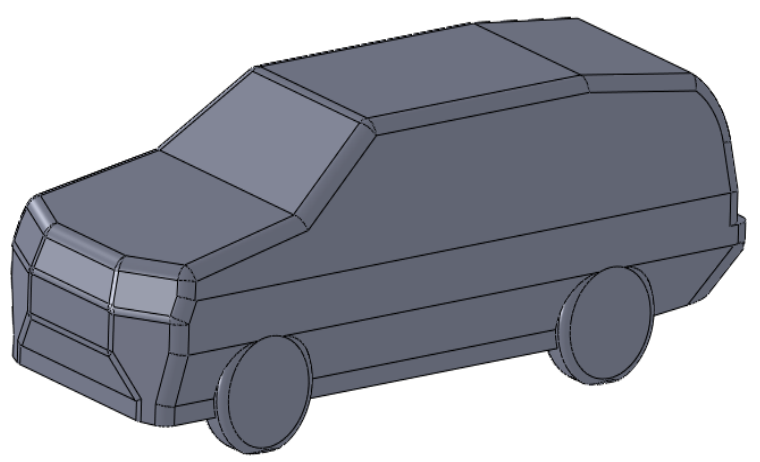

Figure 2. General View of Vehicle Basic Model

Schematic representation of model in the wind tunnel is shown in Figure 3.

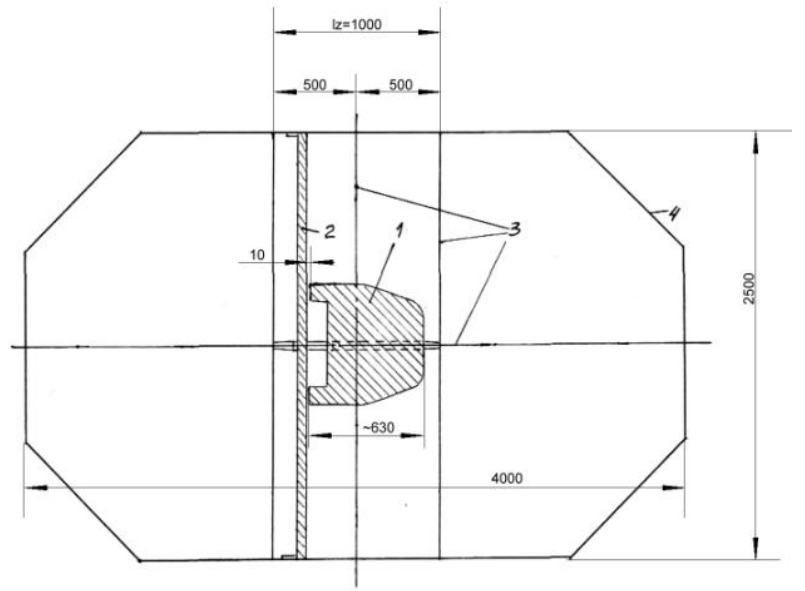

Fig.3. Diagram of Vehicle Model Installed in Working Section of Wind Tunnel (front view)

( 1 - vehicle model; 2 - vertical road-simulating screen; 3 suspension link of six-component electrotensometry balance;
4 - contour of cross-section of working section of wind tunnel)

Preliminary results with different passive devices indicated that large drag reduction was achieved by two options and these are "rear screen" and "rear fairing. The paper will discuss results for these two options.

Paper will also present preliminary results from two other passive methods, astructure in the front and vortex generator on the top at the rear of the model.

The main results are given in comparative form (in percent) as the base drag coefficient varied due to uncertainty in test set up. For each device testing, first the base case drag coefficient was obtained, and then devices were installed and drag coefficient was obtained.

\section{SETTING OF TASK TO TEST A MODEL WITH REAR SCREEN}

6)

Rear screen is a plate, installed at vehicle's back (Fig.4-

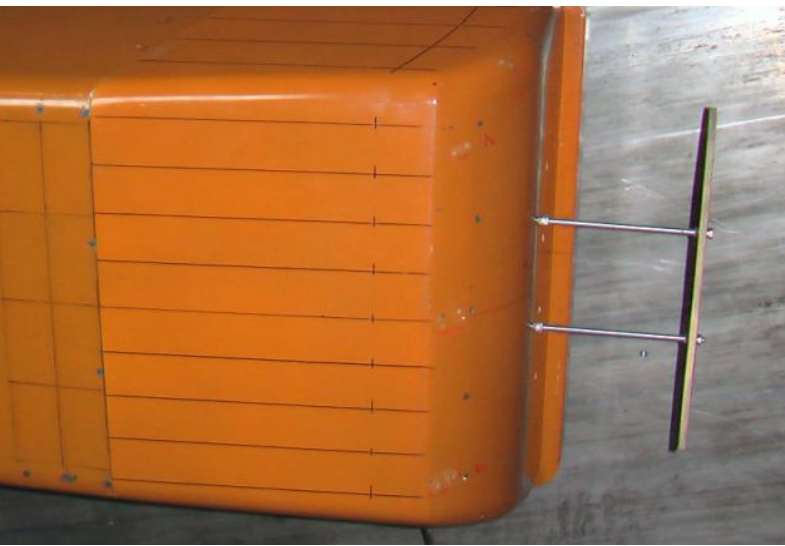

Fig.4 Vehicle's Rear Part with Rear Screen

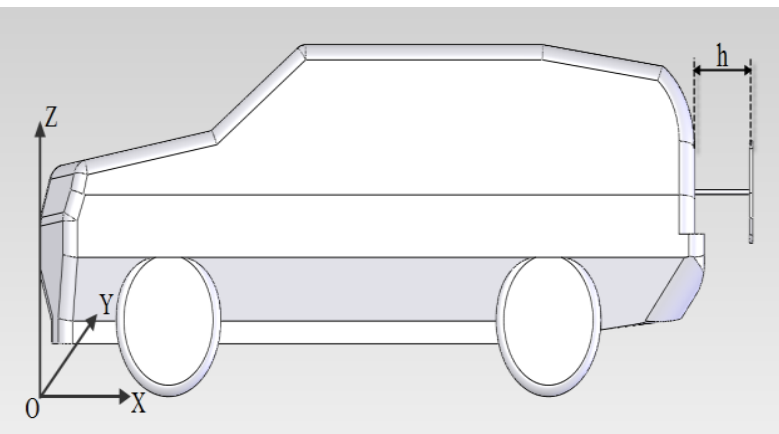

Figure 5. Side view of rear screen 


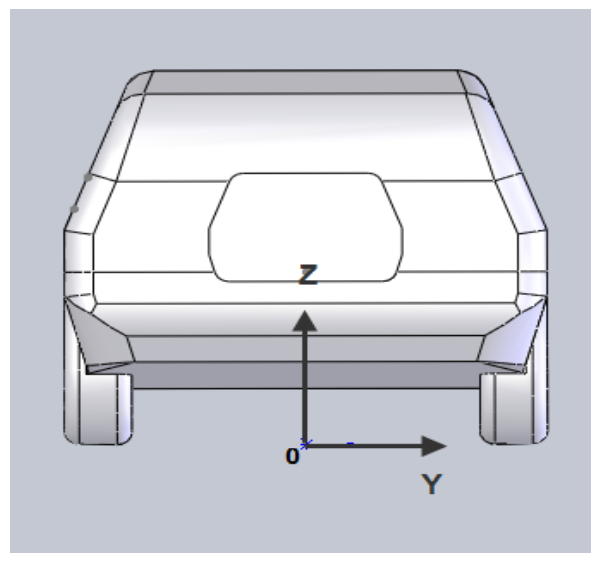

Figure 6. Rear view of rear screen.

The expected effect of aerodynamic drag reducing is achieved for the sake of vortex that originates between vehicle model's rear wall and screen; the vortex enables no-separation flow of external air flux. This results in bottom trace narrowing and thus to reducing of base drag for the sake of pressure increase.

The screens were installed at various distance $h$ from model surface. Screen contour took after back view vehicle contour on a scale of $\bar{D}=0.6$ and 0.8 with the screen thickness of $7.5 \mathrm{~mm}$. Also the tests of screen of $1 \mathrm{~mm}$ thick were also considered with similar scale size of rear part contour ; $\bar{D}^{*}=$ 0.8 and 0.6 .

Also we investigated impact of two screens, installed one after another. The distance between model rear wall and first screen is $\mathrm{h} 1$ and distance between screens is $\mathrm{h} 2$.

\section{RESULTS OF TESTS OF MODEL WITH REAR SCREEN.}

To exclude method error caused by possible inaccuracy of model installation on air flux velocity vector, the tests were done for various incident angles $\beta$. At this the minimum value of any function on parameter $\beta$ corresponds to vehicle's incident head flow without slide angle that can occur in field conditions. In all cases use of rear screens reduces vehicle model's aerodynamic drag. Among the investigated cases the most effective one was use of screens $\bar{D}=0.6 ; \bar{D}^{*}=0.8$ and; 0.6 and the resistance decrease was $5.5 \%$ to $6.5 \%$ (Fig.7).

Table 1 shows that there is optimum gap for theleast drag coefficient.

Visual observation let to see vortex in the clearance between screen and model's rear wall, at least, on top. On sides flux stall was observed directly behind the model. It is worth mentioning that for this vehicle configuration it was not possible to form stable oval vortex in the clearance between screen and model's rear wall, which could provide more aerodynamic drag reducing. Preliminary CFD calculations also showed higher pressure behind the screen that provided additional reduction in opposing force.

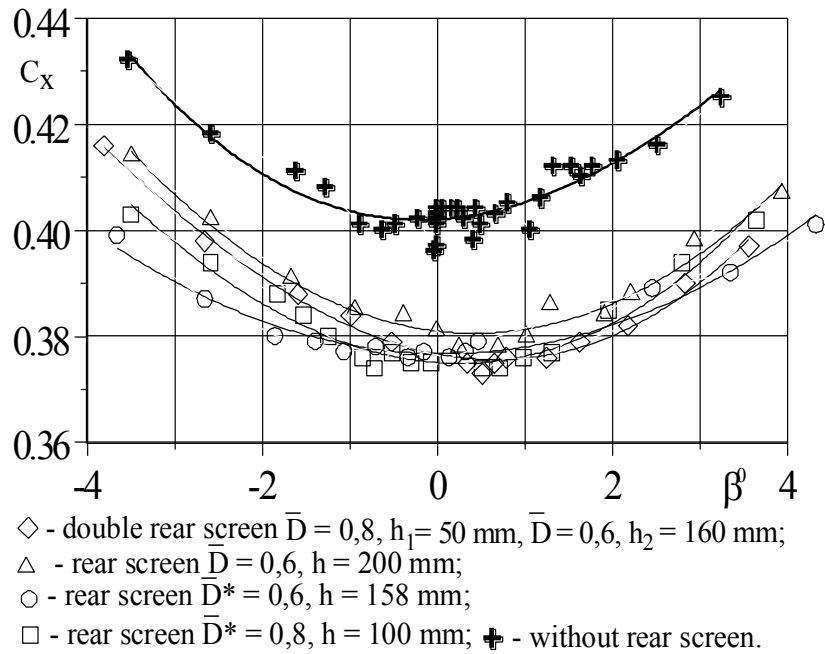

Fig.7 Impact of Rear Screen on Aerodynamic Drag Factor $C_{x}$.

Table 1, Effect of gap on drag coefficient-rear screen $\overline{\mathrm{D}}=0.6$

\begin{tabular}{|c|c|}
\hline $\mathrm{h}, \mathrm{mm}$ & Cxmin \\
\hline 224 & 0.378 \\
\hline 200 & 0.378 \\
\hline 158 & 0.387 \\
\hline 100 & 0.392 \\
\hline $\begin{array}{c}\text { Without rear screen (base } \\
\text { drag coefficient) }\end{array}$ & 0.402 \\
\hline
\end{tabular}

\section{SETTING OF TASK TO TEST MODEL WITH REAR FAIRING}

The second investigated means of aerodynamic drag reducing, the so-called rear fairing, implies a structure in vehicle's back part, included into the separation area, and, in a perfect case, providing no-separation flow of modified configuration vehicle model (Fig.8).

Results of the investigations are useful for analysis of basic means of possible reducing of aerodynamic drag for estimation of minimum possible values; they are of academic value. The purpose of tests was also obtaining of experimental test base for testing of design methods and analysis of possibility of separated flow design simulation.

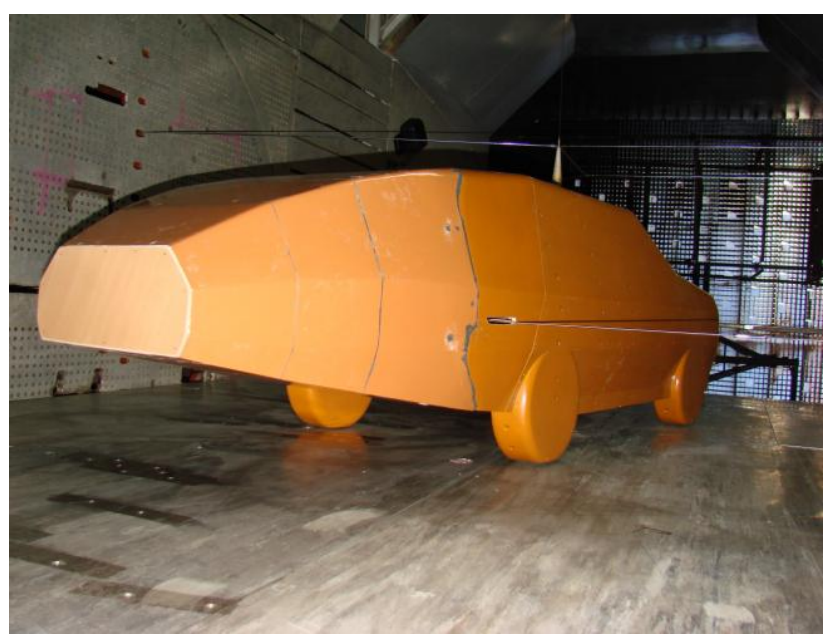

Figure 8. Vehicle Model with Four-Section Rear Fairing 
Here are several configurations of rear fairing of various length, schematically shown in Figure 9.

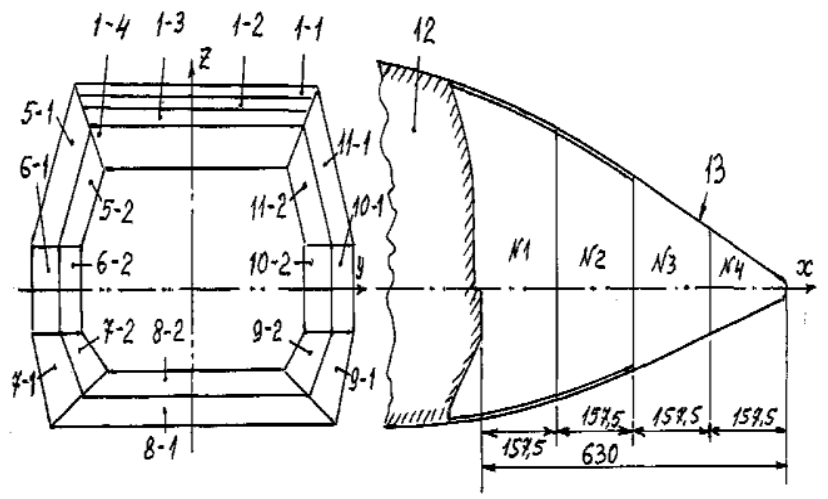

Fig.9. Geometry of Rear Fairing

\section{RESULTS OF TESTS OF MODEL WITH REAR FAIRING}

Results of aerodynamic drag force factor are shown in Figure 10

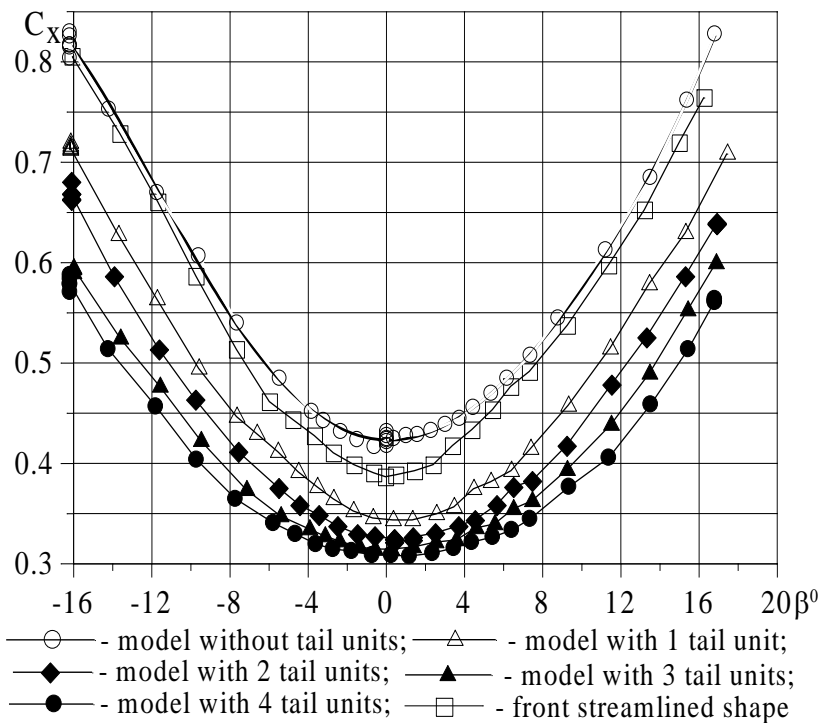

Fig.8. Dependencies of Aerodynamic Drag Factor of Slide Angle (base drag coefficient $\mathrm{Cx}=0.415$ )

The series of tests accomplished allowed to work out various approaches to reduce aerodynamic drag, used in aviation. For example, tail pieces of aircraft (fuselages, nacelles, chassis nacelles, suspensions) are supplied with rear fairing.

Use of idealized aft rear fairing for the vehicle model under consideration also showed high efficiency of such a structure. At installation of full-size rear fairing, head aerodynamic drag factor of vehicle model has decreased by 26\%. Half-length truncated rear fairing also has high aerodynamic efficiency and allows to reduce aerodynamic drag factor by $22.6 \%$. At aft rear fairing length being $25 \%$ of its full length vehicle model drag factor is reduced by $16.1 \%$.

\section{ADDITIONAL CONCEPTS}

Additional devices were tested to reduce drag.

Structural elements that localize the area of flow detachment (edging) shown on figure 9 and figure 10 were attached to the front of the model. This elements have to create return zones with low pressure (figure 11) on the edge of car. Same investigation was providing in [9].

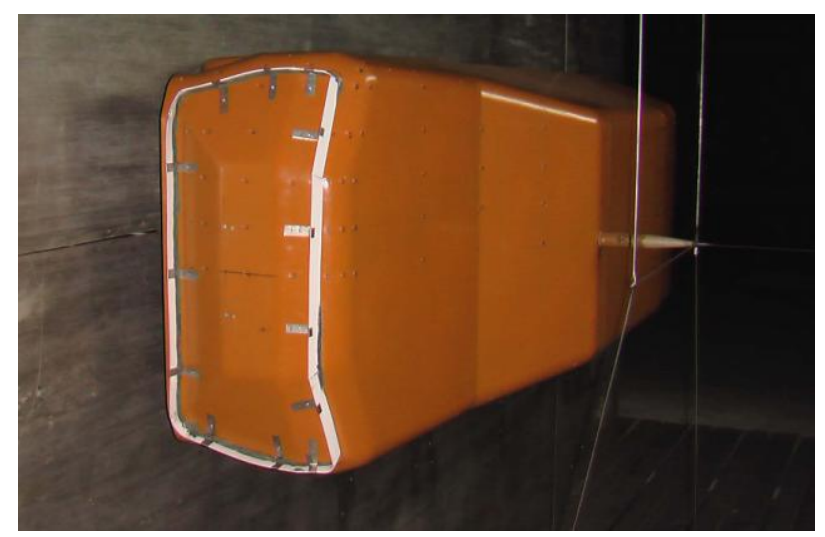

Fig.9. Structural elements that localize the area of flow detachment (circular edging)

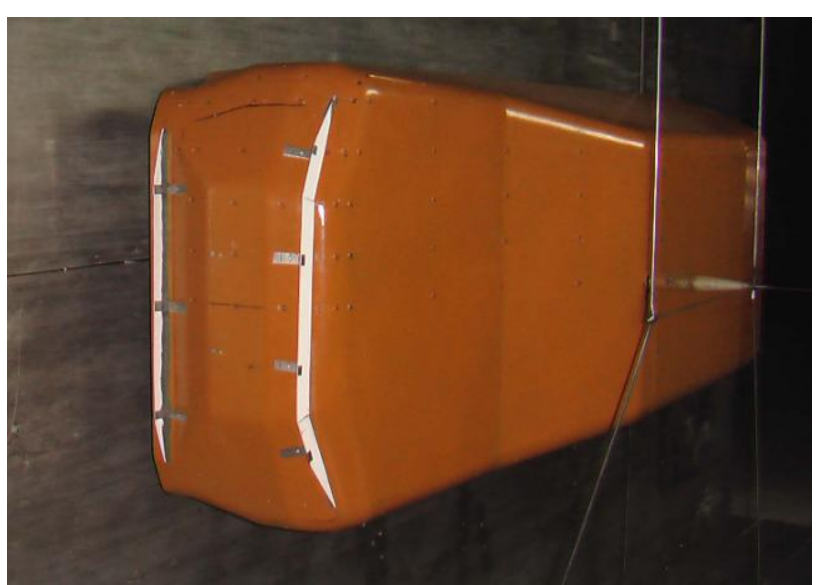

Fig.10. Structural elements that localize the area of flow detachment (only up and down edging)

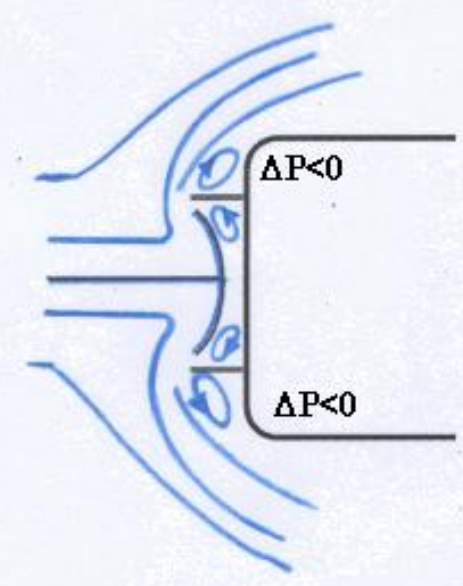

Fig.11. The schema of flow with edging 
The distance between edging and front edge of car model $b$ and also the height of edging $h$ were varied in the tests. The height $\mathrm{h}$ was changed from $15 \mathrm{~mm}$ to $25 \mathrm{~mm}$ and the distance $\mathrm{b}$ was changed from 30 to $60 \mathrm{~mm}$. The investigation of two form of edging was provided - the ring edging in front part of car (figure 9) and upper and down edging on front part of car (figure 10).

The results of investigation for optimal values of $h$ and $b$ are shown in Table 2.

Table 2, Effect of gap on drag coefficient- Structural elements that localize the area of flow detachment

\begin{tabular}{|l|c|c|}
\hline $\begin{array}{c}\text { Structural elements that } \\
\text { localize the area of flow } \\
\text { detachment }\end{array}$ & $\Delta \overline{\mathrm{C} x} \%$ & $\begin{array}{c}\text { Base drag } \\
\text { coefficient } \\
\mathrm{Cx}\end{array}$ \\
\hline $\begin{array}{l}\text { Edging having only upper } \\
\text { and down elements on } \\
\text { distance } 30 \mathrm{~mm} \text { with height } \\
\text { of } 25 \mathrm{~mm}\end{array}$ & -2.24 & 0,392 \\
\hline $\begin{array}{l}\text { Ring edging with height of } 15 \\
\mathrm{~mm} \text { and on distance } 60 \mathrm{~mm}\end{array}$ & +1.74 & 0,392 \\
\hline
\end{tabular}

Also was conducted research vortex air flow generators placed on the back edge of roof. Three variants of vortex was tested (figure 12). In this option, the net change in drag coefficient is result of balance between increase in drag due to the device and reduction in drag due to reducing flow separation.

For VG1 vortex generator, the distance from rear edge of car was changed from $36 \mathrm{~mm}$ to $60 \mathrm{~mm}$, the height of vortex generator was changed from $12 \mathrm{~mm}$ to $25 \mathrm{~mm}$ and angle of setting was changed from $15^{\circ}$ to $18^{\circ}$. There were seven vortex generators.

For VG2 vortex generator, the number of vortex generating elements varied from 24 to 30 (Figure 13). The distance from rear edge is $30 \mathrm{~mm}$, the height of the elements is $10 \mathrm{~mm}$.

For VG3 vortex generator, the number of elements varied from 16 to 24 (Figure 14)
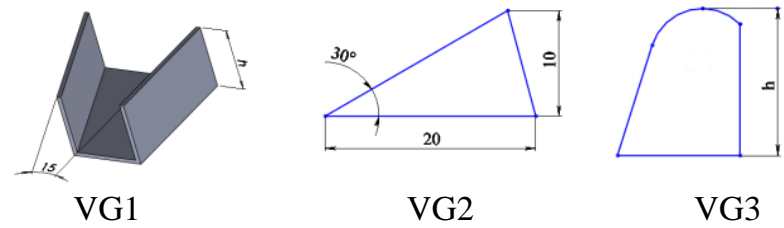

Fig.12. The types of vortex generators.

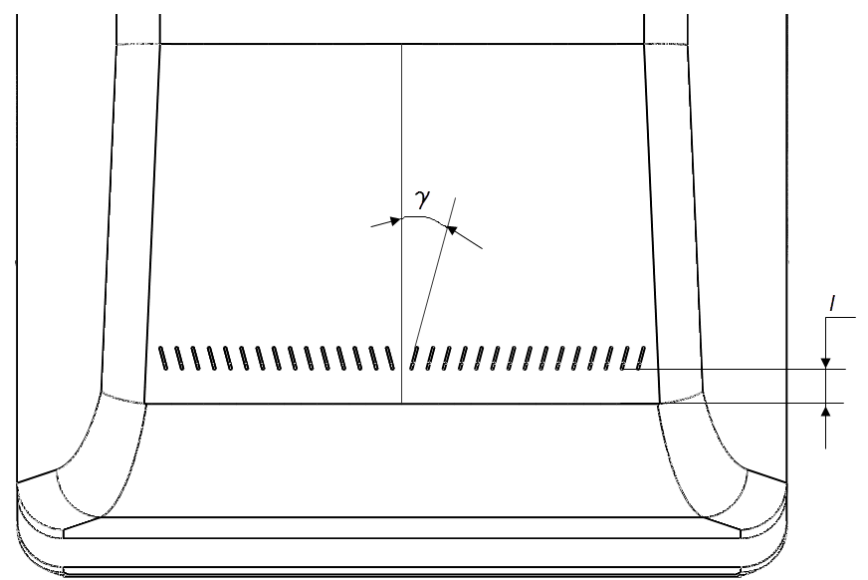

Fig.13. VG2 vortexes
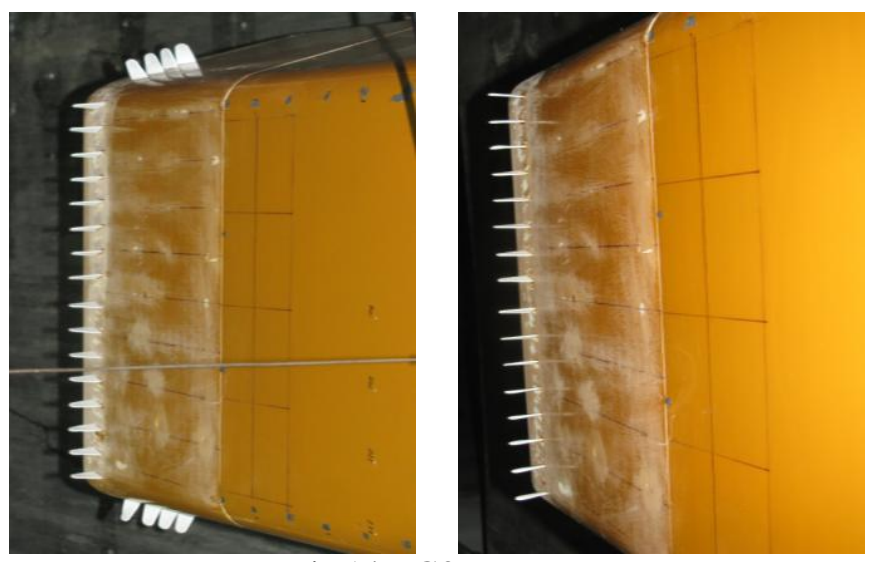

Fig 14 VG3 vortexes

The test results for the best combinations of geometric parameters are shown in table 3 .

Table 3, Effect of Orientation of Plates of Vortex generators on drag coefficient

\begin{tabular}{|l|c|c|}
\hline \multicolumn{1}{|c|}{ Type of Vortex Generators } & $\begin{array}{c}\Delta \overline{\mathrm{C} x} \\
\%\end{array}$ & $\begin{array}{c}\text { Base drag } \\
\text { coefficient } \\
\mathrm{Cx}\end{array}$ \\
\hline $\begin{array}{l}\text { Vortex generators (VG1) on } \\
\text { the roof it the rear part, 36 } \\
\text { mm distant from the edge }-7 \\
\text { elements., step of } 70 \mathrm{~mm}, \gamma= \\
15^{\circ}, \mathrm{h}=20 \mathrm{~mm}\end{array}$ & +0.25 & 0,392 \\
\hline $\begin{array}{l}\text { Prism-shaped vortex generator } \\
\text { (VG2) on the roof in the rear } \\
\text { part, 36 mm distant from the } \\
\text { edge-30 elements, } \gamma=0\end{array}$ & -1.24 & 0,392 \\
\hline $\begin{array}{l}\text { Vortex generators (VG3) with } \\
\text { Clark type profile. } \\
8 \text { elements from every side of } \\
\text { longitudinal axis mowing a } \\
\text { stream from lateral surfaces to } \\
\text { the centre }\end{array}$ & -0.26 & 0,389 \\
\hline
\end{tabular}

The tests with elements that localize the area of flow and air flow vortex generators have not given a considerable positive effect and will require additional analysis.

\section{CONCLUSSIONS}

1. Use of rear screen allows a reduction in aerodynamic drag of the vehicle model under consideration by up to $\sim 6.5 \%$. Efficiency of rear screens from point of view of drag reducing equally depends on configuration, dimensions and arrangement of screens as well as on model's rear part configuration. The external mount of spare tire can be arranged to reduce drag.

2. Rear fairing as part of flow separation area behind the vehicle can reduce aerodynamic drag of the vehicle with investigated configuration, by up to $26 \%$. These results can be used at analysis of accuracy of calculation methods for defining aerodynamics of vehicles with separated areas. The 
results can also be useful for designers and design engineers in selection of vehicle external configuration.

3. The other passive options also have potential to reduce drag. Front structural elements showed decrease in drag coefficient up to $2.24 \%$ and vortex generator showed a decrease up to $1.24 \%$. There is scope to achieve additional improvement with the understanding of flow field and optimization of design.

\section{AKNOWLEDGEMENT}

We would like to thanks Bahram Khalighi (General Motors Global R\&D, Vesicle Department Research Lab, USA) and Alexey Ushakov (Chief Scientist for Eastern Europe GM R\&D Office) for their help and guidance in this research. This research investigation was done under Department of Energy program of Global Initiative for Proliferation Prevention grant (BNL-T2-370-UA).

\section{REFERENCES:}

1. W.H.Hucho - "Aerodynamik des Automobils" - p.158161 - Vogel Verlag, 1981.

2. "Experimental Research of Vehicle Model Type RAF", KHAI, 1990.

3. Masaru Koike*, Tsunehisa Nagayoshi*, Naoki Hamamoto* - "Research on Aerodynamic Drag Reduction by Vortex Generators". Mitsubishi Motors/ Technical Review, 2004. No 6, pp.1-16.

4. S.P.Zagorodnikov - "Modeling of road in wind tunnel tests» - News of higher education institute. Machine building. 1980 .

5. Carr G.W. The Study of Road Vehicle Aerodynamics Using Wind Tunnel Models. Paper 14, Proc. 1st Symp. Road Vehicle Aerodynamics, London, 1969.

6. Technical report of Kharkov Aviation University. 